occupations, cancer houses, and many others can only be settled after statistical and other investigations have been made and checked and cross-checked, controlled and recontrolled by each other. Such investigations are beyond the means and powers of individual science workers or of medical institutions, and need to be undertaken by an organized body with relays of workers and sufficient funds at its command to provide for the uninterrupted pursuit of the inquiries.

Katz, of Hamburg, whom I have previously quoted, remarked: "It is to be deplored that Cohnheim's doctrine has so long found an extended acceptance, for the further development of cancer research would have, through it, no value. A standstill would result from the fatalism which underlies this theory. The same may be said with regard to Ribbert's theory, which, though of far later date than Cohnheim's, is in pursuit and continuation of it:"

But a theory, if it has the evidence of truth, must be minutely and impartially examined, even though it seems to lead to a conclusion which we might wish to escape. There is, however, no occasion for so pessimistic a view as that of Katz. The "tumour-germ" theory, at least does this : it convinces us of the local origin of cancer, and of the positive curability of it if removed quite early and completely. Of course, it does not guarantee one against the formation of another malignant new growth, any more than the repair of a broken bone guarantees one against the occurrence of another fracture. It should also encourage the early and more frequent removal even of benign growths. Future researches may reveal a method whereby a special inhibitory influence may be brought to bear upon the cells of the "tumour matrix," on the lines tried by Foulerton; or a restraining, even a strangulating, effect upon the tumour cells by the tumour matrix may be produced, as suggested by Marshall. But in any case, we can reasonably hope and expect that the organized researches now commenced by the Colleges will in time yield much information as to how to prevent cancer by teaching us what are the real agencies which stimulate it into existence.

In bringing these remarks to a conclusion I will borrow the description recently given by Mrs. Crawford of the mind of the late M. Thiers, and apply it to the theory founded by Durante and Cohnheim. "It has search-light luminosity. Like radium, it keeps burning brightly, without consuming itself." And, I would add, it will not only remain active and brilliant to the end, but it will, I believe, shed more and more light on the etiology of cancer with every fresh addition made to the science of embryology and to our knowledge of tumours.

1 Arch. Gén. ReFERENCES.

3 Arch, de Méd. Méd., June, I892. ${ }^{2}$ Sem. Med., September 24th, rgoz. Ceritralb. f. Bakt., June, roo3. ${ }^{4}$ Ann. de linst. Pasteur, January, 1903. Bulletin, January, 1898. 8 Lancet, November 14 th (p. 1393) and 28 th (p. 1530), 903. ' Path. Soc. Trans., 1886, vol. XXxvii, p. 354.

\section{THE PARASITIC THEORY OF CANCER.}

\section{BY H. (x. PLIMMER, F.L.S.,}

In charge of the Cancer Laboratories, Lister Institute of Preventive Medicine, and Cancer Hospital, Brompton.

Few things, even in medicine, have ever been so tangled as the views which are held by different people on the origin and cause of cancer, and few subjects have suffered so much from extremes of opinion, from no parasites to all parasites. The too hasty and too certain views of many workers (some of them founded on the examination of only one case) have made the thinking heads in our profession very shy of theories, and the critics work easy, or apparently so. But the battle around cancer still rages. Is it parasitic or not parasitic? The parasitic theory is by no means yet extinct, although some would have us believe so, especially those who are more willing, as are many, to talk about cancer than to work at it. I shall try to give some reasons why I think we dare not at present give up the parasitic theory of cancer, and I shall try to show that this theory is rot founded entirely upon speculations, but that it has sprung really from wider clinical and biological considerations of the subject.

The idea that cancer is an infectious disease is an old one: so long ago as i 797 it was classed amongst infectious diseases by the Prussian sanitary laws. But the question only came actually into practical pathology after the development of bacteriology: then the differences between cancer and the other bacterial infectious diseases gave rise to the view (after a very short-lived cancer bacillus) that it may be due to an organism of another kind, one on the animal side-a protozoon-and to this view Metchnikoff gave his support.

In reviewing the present position of this question I shall first consider it from the more general points of view, and shall then proceed to a more special examination of cancer itself, so far as concerns the present subject.

There can be no doubt that during the last few years there has been a considerable increase in the number of cases of cancer, and this increase is out of all proportion to any known general cause except a parasite. There are also on record many instances of relative increase in the frequency of cancer, which may be called epidemics of cancer, and it is very difficult to see why there should be such increase if the etiological factor were a constant one, but these epidemics are easily explainable from the parasitic point of view. The facts that the death-rate from cancer is in many districts $a b$ normally high, and that it varies greatly in the same district at different times, so that, as in other epidemics, a sudden increase in the number of cases occurs in certain years, seem only able to be explained by the presence of a parasite, which in certain places and times finds better conditions of existence for itself

Again, the disease has been shown to have a predilection for low-lying, damp districts, and especially for districts which have both wood and water; and of late years a number of observers, both here and abroad, have brought forward a quantity of facts showing its incidence in certain houses"cancer houses" they are even called-all of which points most urgently towards a parasitic origin.

Behla, who lived for a great number of years in Luckau, has made a most careful study of the occurrence of cancer in the various parts and houses of the town and its suburbs; and he showed that in certain parts the incidence was extremely high, and that in other districts there was none. The history is so remarkable, and I think so important as evidence for the parasitic theory, that I will briefly re-tell it. Luckau is a town with 5,000 inhabitants, 3,000 being housed in the central part, or town proper, and 1,000 in each of the two suburbs which flank it east and west. The population is agricultural, and during the years from 1875 to 1898 remained the same in number; their habits and ways of lile also remained unchanged. Between these years the deaths from cancer numbered I out of $25-30$ for the entire town; I out of 9 for the eastern suburb; and in the western suburb there was not a single case. The houses were similar in size and arrangements, and were, as a rule, damp. The soil of the main town and eastern suburb was moist, and lay low; that of the western suburb was, on the contrary, sandy, dry, and elevated. There was a large ditch which encircled the central town and the eastern suburb, not touching the western suburb, and the cancer followed closely the course of this ditch; the cases in the main town occurred chiefly in those houses whose gardens bordered on the ditch, and in the eastern suburb all the gardens were watered from the ditch. There were 127 houses in this quarter, and 56 of these were cancer houses, 43 with I case each, 10 with 2 cases, 2 with 3 cases, and I with 4 cases. The ditch contained foul stagnant water with which the people watered and washed their vegetables many of which were eaten raw. In Behla's opinion the probable source of infection-for such he considers it must be -was in the uncooked vegetables; and in this connexion I may mention the case of a very distinguished patholngist who, for the same reason, gave up eating salad and uncooked vegetables to my knowledge more than ten years ago. The figures of the city of Buffalo are also very striking with regard to this point. Dr. Lyon, in studying the cancer statistics of Buffalo for a period of twenty years, found that, roughly, for the same population, the cases of cancer in the German wards of the city were double the number of those in the native wards, and he mentions the fact that the Germans usually grew some vegetables, and were in the constant habit of eating many of them uncooked.

Apart from the question of uncooked vegetables, these figures are striking enough, and it is much to be hoped that more inquiries similar to Rehla's will be nndertaken elsewhere, with the care and intelligence which characterize his work.

How can we explain this occurrence in certain regions? How can we explain the increase of cancer at the present time? Is it that Nature does not now do her work so well as she did formerly, and that there are now more people than 
there were years ago with bits of detached embryonic tissue in them?

Can we really believe that in all these people who make up this increased number of sufferers from cancer there are chance embryonic vestiges; that in all there has been some chance traumatic influence, or a chronic inflammation; or that they have all already a latent cancer? It surely accords far better with our experience that a parasite should be at the bottom of all this ; which parasite, in some places and in some years, can increase and spread better, on account of some more favourable conditions of existence.

In the formation of a cancer there must be a cause for the cell proliferation being so greatly in excess of that of the normal growth processes, otherwise it would not be possible for one cell or a small group of cells to become in a short time relatively so great in quantity. Will the theories of those who ale opposed to the parasitic view explain this peculiar and destructive cell proliferation? The theory of the formation of cancer from embryonic remains will not as it often arises in parts where these rudiments have not been found, and moreover those tumours which can with some reason be attributed to this cause are not as a rule malignant.

Von Hansemann's view that cancer arises from a cell which has become essentially altered and then has suffered from some peculiar irritation does not take us far, neither does it shut out the view that this alteration and irritation may be due to a parasite. He says that if this irritation affect a normal cell we get a hyperplasia, and if it affect an anaplastic cell-that is, a cell which has from some cause become or other essentially altered, which grows in a way in which it did not before, and which behaves more like an embryonic cell-we get cancer. But what is the cause of the anaplasia, and what is the irritation which sets the anaplastic cell going towards cancer?

Ribbert's view is even less satisfying. He suggests that there is a possibility that inflammation arising in a tissue may destroy the continuity of certain epithelial cells and set them free, and that the isolation of these cells from their proper surroundings determines the formation of cancer.

Von Hansemann, whose two books on tumours are, in my judgement, the best we have upon the subject on the pathologico-anatomical side, says that he does not believe that any irritation acting alone on a normal tissue can produce a malignant tumour, as Ribbert suggests : neithor do I.

Let us now examine cancer more closely from the parasitic standpoint, and I think it will be possible to show that in cancer wo have, without exception, all the lesions of a chronic infectious disease.

One of the finctions of epithelium in the normal state is that of protection against external influences, organized agents, and chemical poisons. We know that in us the epithelium is harder and more abundant in those parts which are exposed to pressure or injury; for instance, the epithelium of the mouth and tongue is always more abundant than that in regions of the body less exposed to injury-the stomach, for instance. We also know that epithelium proliferates in direct ratio to any irritation which is applied to it. The hard patches on the hands of certain workmen, corns, the thickened epithelium of the tongue in smokers, are cases in point. But these epithelial proliferations disappear when the cause is removed. Further, epithelium is a barrier against solid particles, living or dead, for instance, the micro-organisms in the respiratory passages and in the intestine are not able to penetrate the epithelium so long as this maintains its vitality, or is not injured. It is also a harrier to chemical poisons. Compare, for instance. how slowly morphine can get into the body through the unbroken skin, through the stomach even, and the speed of its absorption when injected hypodermically, where the epithelial barrier does not come into play.

Let us think of epithelium now in connexion with cancer. A cell is infected by a parasite which has penetrated it. It may give rise in the cell to a local lesion only, and may become encysted in the coll, as actually happens in the case of the parasite $\dot{K}$ lossina helicina in the kidney of the snail. But supposing the parasite should produce a poison, then the neiglbouring cells will be irritated, and will react, as normal cells do to irritation, by proliferating ; they will then group themselves around the infected cell, and will continue to proliferate so long as the irritation remains, thus fulfilling their function of preventing the further penetration of the parasite into the tissues, and of preventing the absorption of the poisons. The parasite multiplies, and in consequence more cells will multi- ply, and will eventually destroy the fixed-tissue elements in heir vicinity.

With regard to the stroma, this can be considered as the phagocytic reaction of the organism against the invasion of the parasites and the cells in cancer. In any part the action of the tissues is the same against an invading organic body. The normal connective supporting tissue of the part is damaged or destroyed, as above mentioned, and a new cicatricial tissue is formed, which, with the amoeboid phagocytes, dnes its best to destroy the cancer cells.

This description of a cancer is not by any means fanciful, as it can be seen and followed under the microscope Clinically, too, the effect of this phagocytic reaction has beer. known for long years, since it was long ago taught that the harder a cancer was so much the less likely was it to become generalized. Many cases of cancer show the primary growth practically cured, the patient having died from metastases With regard to the metastases, no doubt many cells get detached from a cancer which do not form metastases; one can often see in a lymph-gland cancer cells undergoing destruction there, and no cancerous infiltration of the gland; but if a cell containing a parasite should get detached and lodged somewhere, it would possess both the necessary protection against the cells amongst which it landed by means of the possible secretion of some noxious body, and at the same time the stimulation to division and multiplication. From the above it will be seen that the essential lesion in cancer is an epithelial lesion, which is most naturally to be explained by an intracellular parasite, and the tumour is the result of the reaction of the organism against this parasite and the cells which it has made cancerous.

Let us now look a little closely at the objective signs of this parasite in cancer. It has been known for a long time that there are certain definite bodies which are found in cancer, generally embedded in the cytoplasm of the cancer ceils, but which are sometimes found also in the nucleus, or free between the cells. These are round bodies, from about $0.004 \mathrm{~mm}$. to $0.04 \mathrm{~mm}$. in diameter, and they contain a very small more or less central body, surrounded by a very delicate substance, which in fixed specimens is irregular in shape and this again is surrounded by a capsule which often has a double contour. These bodies have very definite reactions to certain stains. There are a number of appearances in cance cells which have nothing whatever to do with these bodies such as the ordinary known degenerations, vacuolation, etc. and one of the first things which Rüfer and I attempted, wen we began to work at cancer, was to separate these bodies, by description and drawings, from those appearances in the cells which were due to degenerations, invaginations o other cells, leucocytes, etc. These bodies have still to be reckoned with, as there is no evidence that they are degenerations of nuclei or of nuclear figures, or that they are mucous, colloid, or hyaline drops, or leucocytes; and the theory that they are parasites is not to be wiped out by a stroke of the pen, as some would have us think. They are found in practically all cancers in the growing, active parts, and not at all il the degenerated parts, and they are not found anywhere else. Some observers, who maintain that they are secretory products, have stated that they are only to be found in breast cancers; but this. I take it, means that they have not had patience to examine sufficiently, or rightly, cancers from other parts.

There is one method of examination of cancer which should be preferred to all others, or which at least should be used to control all others; that is, the examination of the living cells in their own juices, or in serum, on the warm stage. No stained specimen is, I think, so convincing that the bodies in question are organisms separate and distinct from the cells and moreover, the ordinary degenerations can be by this method very easily differentiated from the bodies. Personally. I would take no one's opinion on the morphology of this $\mathrm{nr}$ any other organism or tissue, unless I knew that it had been examined fresh and unstained. It is a method at present but little used, as it is delicate and difficult in manipulation and takes much time, and necessitates withal a systematic schooling of the eye, and a knowledge of how to use the microscope. The cancer cells by this method can, with the leucocytes, be kept alive for many hours, even days, and the changes, which many regard as multiplication, in the bodies can be observed.

I will now take the points up a little more in detail. I have stated that these particular bodies are found in practically all cancers, and I am speaking from an experience of about 1,500 cases. In the New York State Pathological Laboratory at Buffilo 
a systematic investigation has been undertaken with a view of testing my statement, and from Dr. Gaylord's report it will be seen that they completely substantiate my claim "that these bodies are present in all carcinomata." Those who have failed to find them in epitheliomata must bear in mind that they do not occur in like quantity or manner in all cancers. In epitheliomata, for instance, they occur in patches: and you may cut many sections and find none, and may then come across a section containing a large number. This may be compared with the occurrence of the tubercle bacillus in lupus, where the bacilli occur sparingly compared with their plenteous distribution in the other manifestations of tubercle.

I have also stated that the bodies are not to be found in other structures, and in this I am confirmed by Professor Benda, of Berlin, who states that after careful search in all kinds of tissues he has only found them in malignant growths.

Nösske, who is strong]y opposed to the view that the bodies are parasites, and believes that they are secretory products, states that he has found them in the epithelium of the normal breast. The specimen in which he showed this, and which was supposed to be from a normal breast, was really taken from a cancerous breast just outside a nodule of cancer, and it was exhibited at the Surgical Congress in Berlin in 1902, and a number of the pathologists there were of the opinion that the epithelium had already begun to undergo cancerous change as in places there were as many as three layers of epithelium. I have often seen the same thing at the apparently healthy margin of a cancer nodule; in fact, one can see the bodies better here almost than elsewhere, and it is, I think, a fact rather in favour of their being parasites than of their being degenerations.

A view which has attracted much attention, from the position of its author, was that of Borrel, which set forth that these bodies were centrosomes. There are two points which render this extremely unlikely. First, the great number of these bodies which may be found in one cell, sometimes as many as 30 ; and, secondly, that normal centrosomes can be found in cells containing the bodies, and can be readily distinguished from them. I have lately been working at this point, and have had no difficulty in demonstrating this fact. Moreover, Benda, who was one of the first to describe centrosomes, speaking at the Surgical Congress mentioned above, said that he also had found, with new methods, the quite normal centrosome in cells which contained numbers of the special inclusions, and he holds, therefore, that Borrel's theory is inaccurate, and does not correspond with facts.

Von Hansemann thinks that the bodies may be artefacts, due to the action of the fixative, which extracts water from some hyaline material embedded in the protoplasm, which in consequence shrinks and forms the central mass of the inclusion. This is negatived at once by the fact that they have such a constant appearance in fresh living cells.

Again, the bodies have been stated by Nösske and Greenhough to be secretion products, and to occur only in the breast. This has been disproved by my own experience in finding them elsewhere (for example, in epitheliomata, as mentioned above), which has been confirmed by Gaylord in America. We have found these bodies in cancer arising from all the various types of epithelium, and many instances of the same fact are also recorded by the earlier writers on the subject.

Lubarsch has suggested that the bodies may be broken down erythrocytes. Cancer cells, no doubt, do occasionally take up erythrocytes, but there is never any difficulty in separating these from the cell-inclusions of which we are speaking. Phagocytic cells in many conditions (for example, typhoid fever) do take up red corpuscles, and it is quite easy, by comparing these, at all stages of destruction, with the cellinclusions in cancer, to see that there is no connexion whatever between them. The bodies, moreover, are often larger than an erythrocyte, and by certain methods of preparation the central bodies of the inclusions can be stained with powerful nuclear stains - such as iron-haematoxylin-which cannot be done, of course, with the englobed erythrocytes. Gaylord relates, in this connexion, that the same interpretation has been given in specimens of his own to the injected spores of Plasmodiophora Brassicae (a recognized parasite) which have been taken up by phagocytes, and which are indistinguishable from certain of the forms of the inclusions in cancer.

As regards colloid, it is interesting to note that in colloid cancers one can see that there is no resemblance whatever between a colloid cell and a parasite, and that these latter are never found in colloid cells, but only in the active, undegenerated parts of the tumour. In cases of skin-cancer in which the tumour has grown into the thyroid one can see again that there is no resemblance in reaction or appearance between the cell-inclusions and the colloid cells, or the colloid material, or that material in the vicinity of the growth which has been altered by its presence.

One of the most ardent supporters of the view that these bodies were degenerations of the cytoplasm or.nuclei of the cancer cells was Pianese, and his large monograph on this subject is constantly cited. His work deals with a great variety of inclusions and appearances, very few of which can be accepted as being the same as the bodies in question; and a later paper of his on a protozoon found in a guinea-pig shows that he appears to have modified his views somewhat as to the interpretation of some of the appearances described in his former work. This protozoon was found in the renal epithelium of a guinea-pig, and Pianese concludes that the extensive karyokinesis in the cells adjacent to the parasite must be due to its presence. These mitoses were found to be often atypical, similar to many forms of atypical mitoses found in cancer. The cells also show many of the degenerative changes (nucleolysis or karyolysis, nucleorrhexis or karyorrhexis) so often seen in cancer. Many of the cells also contained inclusions not dissimilar to some seen in cancer, but Pianese is not sure whether these are stages in the growth of the parasite or cellular changes induced by it. From this paper it would seem that Pianese would not now be quite so dogmatic with regard to some, at least, of the bodies seen in cancer cells as when his book was written.

Some of those who have regarded these bodies as parasites have unfortunately given them various names; they have been classed with the protozoa (on the great authority of Metchnikoff), with the coccidia, and with the grega ri nadae. Then came Sanfelice's work on the production of tumours with blastomycetes, and the ground was shifted. The question became greatly complicated by the undoubted fact that blastomycetes have been isolated by several workers from cancers of various parts, and they have also been-described as occurring in sarcomata, and in some skin diseases. I have myself isolated them from six cases of cancer, four of 'which were not ulcerated, either from the growth or from the glands. Whether these saccharomycetes-like bodies are really blastomycetes or stages in the life-history of organisms of another group (as De Bary, Cuboni, etc., have suggested with regard to the saccharomycetes), I cannot yet say, as they are still under investigation, but they are generally classed with the blastomycetes by most writers on the subject, and are always so classed by. those who have not seen them.

Recently attention has been drawn to the Mycetozoa on account of the connexion of one of them-Plasmodiophora Brassicae-with a disease called Kohlhernie in certain plants, in which certain intracellular forms of this parasite show a remarkable resemblance to the cell-inclusions in cancer. Podwyssozki, who was struck with this resemblance, performed several inoculation experiments. with the spores of this organism upon animals, and succeeded in producing new growths of considerable size, formed from connective-tissue cells, or from endothelium from the lymph spaces. He found that this organism led to the proliferation of the infected cells, which new cells were in their turn invaded by the parasite. Von Leyden and Feinberg, who are the most recent writers on cancer, have also been struck by the resemblance of the cancer cell-inclusions to the amoeboid form of the Plasmodiophora. This organism lives symbiotically with the infected cell, and divides by a peculiar form of division which has been carefully described by Nawaschin, and which, as Gaylord has pointed out, has a very great similarity to certain forms of the cell-inclusions in cancer, which I and others have repeatedly figured, and which some of uts have thought to be connected with the process of division. Prepared ana stained by the same methods, they present appearances, as regards size, shape, structure, and staining reactions, which are indistinguishable from the cell-inclusions in cancer. This resemblance, and the fact that the changes preparatory to division in this parasite are so like forms described in the booies in cancer, although of course no proof, give support to the view that the bodies in cancer may be parasitic. At any rate their great resemblance to a well-recognized parasite should make us pause a little.

From the present point of view the rôle which injury may play in the production of cancer can be explained by the fact, 
which Pfeiffer pointed out years ago, that weak and new tissue cells are the most easily affected by any parasitic infection. There is also a parallel between traumatic tubercle, osteomyelitis, and cancer, all arising at a point of injury; and the deduction does not seem far off that in the case of cancer an infecting agent (as in osteomyelitis and tubercle) is present in the blood or in the body, which, in consequence of the lessened or altered resistance of the part, is enabled to determine the development of the cancer. Behla considers that much which we call Disposition and Inheritance with regard to cancer has its reason in a greater local susceptibility of the skin or mucous membranes, by means of which the infection is favoured.

Noël, thinking of the possibility of a transference of the malignant tree-tumours to man, thinks that possibly the especial frequency of cancer in dwellers in woods may be dependent upon the many scratches, bruises, and other wounds of the surface to which these people are liable.

It is a remarkable fact that skin-cancer is almost entirely confined to the face and hands, whilst on the covered parts it is very rare, and only in my experience occurs there in connexion with warts or cicatrices, or where uncleanliness is common-for example, the scrotum. In the face it is much more frequent in those who do not wash carefully (in several cases I have records that no soap had been used for years), and it begins in corners and depressions, or in warts, which are all difficult to keep clean. Dirt in fact, affording a better nidus for a parasite, ceems to me to play a greater part than injury in the evolution of the disease; for instance, in the lip cancer seems to occur much oftener in connexion with the use of a dirty tobacco-pipe than from cigars, which are very much hotter, and therefore must be much more irritating than a pipe.

That cancer is locally contagious has been known for centuries, long before any thought of parasites-for example, between the upper and lower lips, between the labia, etc. and in the well-known case of Mr. Harrison Oripps, in which carcinomatous infection of the skin of the arm occurred from contact with an ulcerating scirrhus of the breast.

There have now been got together by Behla in Germany, and others in France and England, a large number of cases of cancer a deu $x$ - that is, cancer occurring in people who are living together, which, as the recorded cases accumulate, will form most important evidence for the parasitic view of cancer. Behla has collected with his usual care 19 cases, and Guelliot has brought together 103 cases. At present the material is small, but so important is this part of the question that I have no doubt other workers will soon interest themselves in it.

Closely. connected with this point are the various inoculation experiments from man to animals and from animals to animals. Much is sometimes made of the fact that no attempt at transferring cancer from man to animals has been successful; but that these experiments fail is not against the parasitic view, for we know that there are other diseases, for example leprosy and the acute exanthemata, which cannot be transferred to animals, or the parasite may not be in the stage in which it is capable of transmitting the disease, of which many similar instances are known. Moreover, a cellular parasite may only be able to live in one kind of cell, as in the case of Kohlhernie mentioned above : this recognized parasite cannot be transferred to another kind of plant; it can only be inoculated on a plant of the same species.

This inoculation from animal to animal of the same species has been often successfully done. Hanau was the first to record a positive result, he having been successful in inoculating other rats from a rat he found suffering from cancer. Morau published in 1894 an account of successful inoculations from a cancerous mouse to other mice, and he says the inoculation was always followed by success. Borrel, in this year, has recorded also inoculations from of cancerous mouse to other mice, but his experiments were only successful in I out of ro, but he states also that he put several mice into one cage with two cancerous mice, and that five or six of the others became affected naturally. He says "dans tous ces cas, il semble hien qu'une cruse de contagion locale doit être invoquée." After recounting other experiences, he says: "Tous. ces faits plaident en faveur de l'existence du virus cancéreux," which shows that his opinions have somewhat altered since his paper mentioned above on the bodies found in cancer cells. I may here mention an epidemic of cancer which occurred naturally amongst white rats in the cellar of the Patho- logical Institute at Freiburg: in these instances the cancer was always on the hind part of the body. Still more recently Jensen has published an account of cancer in mice. He attained positive results after inoculations into other mice from a cancerous mouse in from 40 to 50 per cent. Inoculation was also tried upon a variety of other animals, but with negative results. Jensen himself regards the successful cases as simple transplantations, not as an infection; but from what we know of the transplantation of epithelium from the experiments of Loeb and others. I do not think we are bound to accept this deduction. When ordinary epithelium is transplanted it may grow for a short while, but then invariably dies, or is destroyed by phagocytes.

The above instances would seem to show at least that the cancer-cell is the bearer of a parasite, and that this cell is able to grow only in an animal ejusdem generis. Knowing the fate of ordinary epithelium when transplanted, we must, it seems to me, assume that these cancer-cells are at the same time the carriers of a parasite, when the transplantation of a few cells can cause the growth of relatively very large tumours of the same kind.

I think if these things be really so, that cancer can be given by one person to another, and by one animal to another, and that it can occur both amongst man and animals as an epidemic, that a parasite must be at the bottom of it: and it is at the same time possible to conceive, which is sometimes forgotten, that it is quite possible for a disease which is produced by a parasite not to be contagious.

I will just mention briefly the most recent work on this subject. In roor Professor Schueller published a book describing parasites in cancer and sarcoma which has called forth much adverse criticism. He describes bodies occurring in very large numbers in cancer and sarcoma, and he states that his "young organisms" may be the same as the bodies others and I have described, with very careful safeguarding of our descriptions. But he mentions so many other bodies that one is tempted to think that he has gone somewhat too far. Amongst other forms, he places great importance on certain "large capsules" of a golden-yellow colour. These have been stated by some-for example, Dr: Voelcker-to be simply cork cells from contaminated cedarwood oil ; and by others again-for example, Dr. Mohr-who have prepared specimens with every precaution against artefacts, to be bodies which con be demonstrated in all cancers and which may reasonably be said to be parasitic. From the specimens I have seen in Germany I cannot agree with the latter opinion; but as the book, although confused, is published by an earnest worker, I would rather not make any definite statement on the subject until I have completed work which is still in progress on the lines he has laid down.

The next work before me was that published last year by the veteran Professor von Leyden on the parasites of cancer. The cell-inclusions which he regards as parasites are the same as those which others and myself have already described, and he ggrees essentially with my own views on the subject, which have been already discussed. An interesting part of his paper is the comparison of the appearances seen in cancer with those seen in the plant disease Kohlhernie, caused by the recognized parasite Plasmodiophora Brassicae, and mentioned above.

The most recent work on the question is one published a few weeks ago by Dr. L. Feinberg on the cause of cancer, with especial reference to the structure of unicellular animal organisms. The absolute necessity of an exact knowledge of the various unicellular organisms and their complicated Jife-histories became evident to me many years ago, but Dr. Feinberg has been the first to put into practice what must have impressed itself on all those who have earnestly worked at cancer, for quite half of his book is devoted to a very good summary of the latest knowledge of unicellular organisms. He names the body which he considers to be the cause of cancer "Histosporidium carcinomatosum," which I think, in the present state of our knowledge, is unnecessary; and he describes it as consisting essentially of a markedly double-contoured capsule containing a nuclear point in the centre surrounded by a clear unstainable zone, and between this and the capsule is a delicate protoplasm which in many instances is striated radially. From this description, and from his plates, it is evident that this organism is the same as the bodies others and I have alreany described, similar again' to those of von Leyden just mentioned.

He brings out a point of importance with'regard to the 
staining reaction of the bodies, which I can confirm from my own experience. In using the methylene blue and eosin stain of Romanowsky the nuclear point of the cell-inclusion easily stains red, whereas with the ordinary nuclear dyes it is stained only with great difficulty. The zone immediately around this point remains unstained, and the protoplasm stains a faint blue and the capsule a darker blue. This reaction of the bodies to this particular stain is precisely the same as that of the unicellular animal organisms-for example, amoebae, the malarial parasite, the trypanosomata, etc.-and in all these instances there is also the unstained zone i mmediately around the nuclear point.

There has not been sufficient time as yet to confirm or disprove the part of his book referring to the development, multiplication, etc., of the bodies.

So far, then, has this particular part of the cancer question reached. If we consider the points I have brought forward above, it will be, I think, impossible for us to shut out the parasitic theory, for not only does the origin of cancer, but also its growth and the differentiation of its cells, find complete explanation in this theory.

Moreover, it seems to me, if we think of the clinical course of the disease, its beginning in one spot, its extension to distant parts by lymphatic or blood ways, the cachexia out of all proportion to the extent of the disease, the spread by contagion, the occurrence in certain parts of the body, and its return after years of quiescence, we are driven, from this side, too, on to the parasitic theory, in which (as in no other) all these events find their explanation.

Lastly, the only hopeful outlook in cancer would seem to rest, too, on the ground of the parasitic theory, for was it not Pasteur who said that the mind of man shall becomelord over all infectious and parasiti c diseases?

BIBWIOGRAPHY.

I have thought it better not to encumber the above with references, but the following works have been especially mentioned or consulted: Behla,Die geographisch-statistische Methode als Hillfsfactor der Krebsforschung, 1899; Die Krebserkrankungen der Stadt Luckau von 1878, bis 1899 : Veber "Cancer a Deux". und Infection des Krebses. Borrel, Annales de l'Institut Pasteur, 19ox and 1903. Czerny, Beiträge zur klinischen Chirurgie. Bd. xxv. Heft I. Feinberg. Dns Gewebe und die Ursache der Krebsgeschwuilste, 1903. Gaylord, Reports of the New York State Pathological Laboratory, Buffalo; rith Fortschritte der Medicin, 1889. Jensen, Centrabblatt Jir Bakteriologie, I, Bd.XXxiv, 19:3. Lubarsch, Palhologische Analomie und Krebxforschung, 1902. Morau, Archives de Medecine Experimentale, 1894. Nawaschin, Flora, 189. The

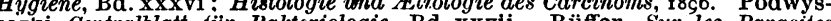

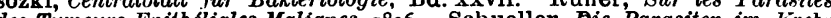
des Tarhs Lither ond sarkom, 19or.

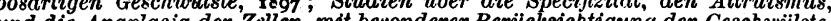
und ale Anaplasia der Zellen, mil besonderer Berichsichtigung der Geschwillste, 1893. Von Leyden, Ueber ale Parnolten des Krebses, Jozz Verhandum Komitees tiir Krebsforschung, 1902 .

\section{THE BEHAVIOUR OF CANCER WITHIN NERVE AND TROPHIC AREAS.*}

[With Special Plate:]

By G. LENTHAL CHEATLE, C.B., F.R.C.S.,

surgeon, King's College Hospital; Italian Hospital; and Hospital for Epilepsy and Paralysis, Maida Vale.

IT would be advisable for those who read this paper to separate the consideration of cancer into three parts. I regard these three headings as essential to the study of carcinoma.

I. The genesis, which includes those matters which appertain to the actual agent which induces epithelial proliferation.

2. The incidence, those matters which relate to the site or soil in which cancer primarily begins ; and

3. The spread, that which concerns the area of occupation of the cancer when considered apart from its secondary deposits.

There can be no doubt that the genesis and incidence must be closely related, but the fundamental influence at work in each may be quite different. I do not intend to enter into the genesis of carcinoma under a separate heading in this paper, but will refer to it during the observations on the incidence and spread of cancer.

The Incidence of Cancer.

In my last paper ${ }^{2}$ I pointed out that there were grounds for considering the incidence of cancer had possibly a direct or

* The substance of two papers recently read before the Pathologic 1 indirect connexion with the nerve area on which it fell. My reason for so doing was. among others, that it is impossible to omit the subject of irritat on from among the etiological factors of cancer. Cancer, and especially squamous epithelioma, more often than not begins upon the actual site of irritation. ${ }^{2}$ As constant irritation applied over a long period produces marked intracellular changes in the ganglia of the posterior sensory roots, it will also probably induce profound physiological changes in the areas of their distributions as well as at the actual sites of irritation.

Again, the incidence of squamous epithelioma and rodent ulcer are very closely associated with the distribution of the fifth cranial nerve. When rodent ulcer is multiple, the points of incidence are nearly always on the area or areas of one or both fifth cranial nerves respectively, and chiefly on thost parts which are not overlapped bo the second cervical spinal nerves (see Fig. I). I also pointed out that squamous epithelioma and rodent ulcer often appeared on those points at which nerves become cutanenus. Dr. Head has described points in the peripheral distribution of the posterior spinal ganglia, which he terms maximum points. ${ }^{3}$ The maximum

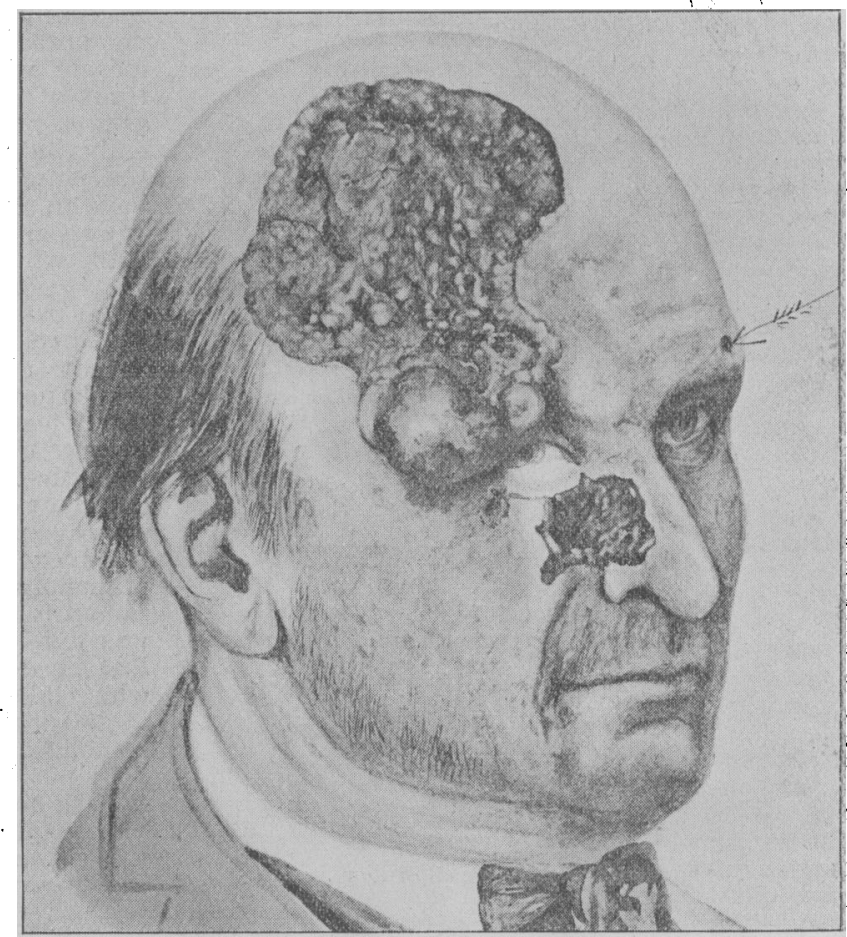

Fig. $x^{5}$-Dr. Colcott Fox's case of multiple rodeut ulcers on one fifth cranial.

points are those fociwithin the areas of referred pain in visceral diseaste at which the paiu is most acute. Herves zoster, when its distribution is complete maps out the whole area oi referred pain, but when incomplete generatly appeas on the maximun points. These maximum ooiuts sonewhat closety correspont to the situations at which nerves become cutaneous. IVhether maximum points are necessarily connected with such sites I do not know. I understand that $\mathrm{Dr}$. Head's maximum points are the maximum points of central inttuene, but I do not know whether even a periplieral nerve can or cannot exhibit or claim its maximal points of central influence. Woddy I attempt to show that the incidence of cancer frequently falls in these maximum points. described by Dr. Hedd I lave Dr. Haad's killa permission to reproduce three plates (Figs. 2. 3, and 4) from the articles to which I have already clirected attention. By comparing the rodent ulcers in Figs. I, 5, 6, 7.8, 9, 10 with the maximum points in Dr Head's plate (Fig. 4), my meaning will be clear. Mr. Hirold Barnard has coliected ten cases of tar cancer in which only one lesion occurred in each case. Fig. II, Diagrams A, B, c, show the distribution of Mr. Barnard's cases. Diagram $\mathrm{D}$ is one of my omn. These cases show points of incidence.

The rodent ulcers are only examples of my meaning; but 